\title{
Shigella in Brazilian children with acute diarrhoea: prevalence, antimicrobial resistance and virulence genes
}

\author{
Mireille Ângela Bernardes Sousa1, Edilberto Nogueira Mendes², Guilherme Birchal Collares', \\ Luciano Amedée Péret-Filho3 ${ }^{3}$ Francisco José Penna 3 , Paula Prazeres Magalhães $1 /+$
}

'Departamento de Microbiologia, Instituto de Ciências Biológicas ²Departamento de Propedêutica Complementar ${ }^{3}$ Departamento de Pediatria, Faculdade de Medicina, Universidade Federal de Minas Gerais, Belo Horizonte, MG, Brasil

\begin{abstract}
Diarrhoeal disease is still considered a major cause of morbidity and mortality among children. Among diarrhoeagenic agents, Shigella should be highlighted due to its prevalence and the severity of the associated disease. Here, we assessed Shigella prevalence, drug susceptibility and virulence factors. Faeces from 157 children with diarrhoea who sought treatment at the Children's Hospital João Paulo II, a reference children's hospital in Belo Horizonte, state of Minas Gerais, Brazil, were cultured and drug susceptibility of the Shigella isolates was determined by the disk diffusion technique. Shigella virulence markers were identified by polymerase chain reaction. The bacterium was recovered from $10.8 \%$ of the children (88.2\% Shigella sonnei). The ipaH, iuc, sen and ial genes were detected in strains isolated from all shigellosis patients; set1A was only detected in Shigella flexneri. Additionally, patients were infected by Shigella strains of different ial, sat, sen and set1 A genotypes. Compared to previous studies, we observed a marked shift in the distribution of species from $\mathrm{S}$. flexneri to S. sonnei and high rates of trimethoprim/ sulfamethoxazole resistance.
\end{abstract}

Key words: Shigella - dysentery - diarrhoea - virulence - drug resistance

Diarrhoeal disease constitutes one of the major causes of morbidity and mortality among infants and young children worldwide. It has been estimated that two-four billion episodes of infectious diarrhoea annually occur in developing countries, resulting in threefive million deaths, with the highest incidence and casefatality rates in children below the age of five years (Sánchez \& Holmgren 2005, Boschi-Pinto et al. 2008, Navaneethan \& Gianella 2008).

The etiological agents of diarrhoea include a wide array of viruses, bacteria and parasites, many of which have only been recognised in the last two decades. Shigella has long been considered an important human pathogen throughout the world, especially in developing countries with substandard hygiene and unsafe water supplies (Ina et al. 2003, Niyogi 2005, Navaneethan \& Gianella 2008, Bhattacharya et al. 2012, Shakoor et al. 2012).

Shigellosis is an invasive infection of the human colon that leads to a spectrum of clinical presentations, from brief watery diarrhoea to severe colitis. Clinical disease generally begins within 24-48 h of ingestion of 10-100 organisms. Watery diarrhoea typically precedes dysentery and is often the sole clinical manifestation of mild infection. However, progression to obvious dysentery may occur within hours to days. Although in most cases supportive anti-dehydration treatment is the cor-

\footnotetext{
Financial support: FAPEMIG, CNPq, CAPES, PRPq/UFMG

+ Corresponding author: ppmagalhaes@ufmg.br

Received 18 February 2012

Accepted 22 August 2012
}

nerstone of diarrhoea therapy, antimicrobial treatment for shigellosis reduces the duration and severity of the disease. According to the World Health Organization (WHO 2005) guidelines, the choice of therapy scheme should be decided by the antimicrobial susceptibility pattern of locally circulating Shigella strains (Niyogi 2005). There are four major subgroups of Shigella, which are classified by biochemical and antigenic characteristics: Shigella dysenteriae, Shigella flexneri, Shigella boydii and Shigella sonnei. S. dysenteriae and S. flexneri are the predominant species in developing countries, while $S$. sonnei accounts for most of the reported cases of shigellosis in developed countries (Nataro et al. 1995, Ina et al. 2003, Niyogi 2005, Nyachuba 2010).

Several virulence factors are associated with Shigella spp. The ability to colonise and invade intestinal cells, resulting in an intense acute inflammatory response, is mediated by plasmidial and chromosomal sequences, such as the invasion-associated locus (ial) (Li-Yan et al. 1993) and the invasion plasmid antigen $\mathrm{H}$ gene (ipaH) (Lüscher \& Altwegg 1994). It has been suggested that ial is responsible for epithelial cell penetration by the bacterium and $i p a H$ also for dissemination from cell to cell (Wei et al. 2003, Parsot 2005).

There are other virulence factors associated with the genus Shigella, such as toxins and iron acquisition systems. Shigella enterotoxin 1 (ShET-1) is a chromosomally encoded, iron-regulated, $55-\mathrm{kDa}$ complex protein that is produced almost exclusively by $S$. flexneri $2 \mathrm{a}$ and only rarely by other serotypes. ShET-1 consists of two types of subunits: one A subunit, encoded by set $1 A$ and five B subunits, encoded by set1B. Shigella enterotoxin 2 (ShET-2) is a 62.8-kDa protein encoded by sen, located on the 140-MDa virulence plasmid. ShET-2 was originally discovered in enteroinvasive Escherichia coli, but 
is produced by many Shigella serotypes (Fasano et al. 1995, Nataro et al. 1995, Noriega et al. 1995, Vargas et al. 1999). The secreted autotransporter toxin Sat is a 107$\mathrm{kDa}$ protein that is chromosomally encoded by the sat gene and was first described in uropathogenic $E$. coli (Guyer et al. 2000). The aerobactin gene iuc is chromosomally located on a pathogenicity island and codes for siderophores, which are compounds associated with iron acquisition (Lawlor \& Payne 1984, Vokes et al. 1999).

Despite the profusion of reports from different parts of the world concerning the aetiology of acute infectious diarrhoea, few data addressing Shigella-associated diarrhoea and organism susceptibility profiles are available in Brazil, especially for our region, where the last population-based study of diarrhoeagenic bacteria was conducted 25 years ago (Queiroz et al. 1987). Furthermore, investigations into Shigella spp virulence markers are still scarce worldwide and we are not aware of any paper on this subject in Brazil. Therefore, we evaluated the prevalence of Shigella and characterised the strains' antimicrobial susceptibility patterns and virulence factors.

\section{SUBJECTS, MATERIALS AND METHODS}

Patients - The study group consisted of 157 children ( 83 male and 74 female, age range 1-48 months, mean age 11.7 months, median 8 months) presenting with acute diarrhoea who sought treatment at the Children's Hospital João Paulo II/Hospital Foundation of the State of Minas Gerais, Belo Horizonte, state of Minas Gerais (MG), Brazil. All patients were from low socioeconomic strata and had no history of hospitalisation or antimicrobial therapy in the 15 days prior to sample collection. Between March 2004-March 2005, passed stool specimens were prospectively collected and transferred to two sterile leak-proof screw-cap collectors (J Prolab, São José dos Pinhais, state of Paraná, Brazil), one of which contained a transport medium of equal parts glycerol and $0.033 \mathrm{M}$ phosphate buffer. The specimens were transported to the laboratory in an ice bath within $1 \mathrm{~h}$ of collection.

Faecal leukocyte detection - To detect leukocytes, faecal smears were stained with May-Grünwald-Giemsa and examined under bright field microscopy at $400 \mathrm{X}$ and 1,000X magnification.

Shigella identification - The specimens transported in buffered glycerol were used to isolate Shigella on MacConkey agar and SS agar media (Difco, Sparks, MD, USA). Faecal specimens were also inoculated into tetrathionate broth (Acumedia, Baltimore, MD, USA) and, after incubation for approximately $18 \mathrm{~h}$ at $35^{\circ} \mathrm{C}$, were subcultured on SS agar. All agar cultures were incubated for up to $24 \mathrm{~h}$ at $35^{\circ} \mathrm{C}$. Approximately five lactosenegative colonies from each agar medium were picked and inoculated into triple sugar iron agar (Acumedia), EPM (Toledo et al. 1982a), MILi (Toledo et al. 1982b) and citrate media (Biobrás, Montes Claros, MG, Brazil). Whenever possible, morphologically different colonies were selected. Following identification, Shigella isolates were antigenically characterised with polyvalent antisera, as recommended by the manufacturer [Probac, São Paulo, state of São Paulo (SP), Brazil].
Antimicrobial susceptibility test - The antimicrobial susceptibility profiles of Shigella strains were investigated using a standard agar diffusion method with ampicillin $(10 \mu \mathrm{g})$, ceftriaxone $(30 \mu \mathrm{g})$, ciprofloxacin $(5 \mu \mathrm{g})$, nalidixic acid $(30 \mu \mathrm{g})$ and trimethoprim/sulfamethoxazole $(25 \mu \mathrm{g})$ (Cecon, São Paulo, SP, Brazil). Screening for organisms producing extended-spectrum $\beta$-lactamases (ESBLs) was performed with ceftriaxone $(30 \mu \mathrm{g})$, ceftazidime $(30 \mu \mathrm{g})$, aztreonam $(30 \mu \mathrm{g})$ and cefotaxime $(30 \mu \mathrm{g})($ Cecon). E. coli ATCC 25922 was included as a reference strain for antimicrobial susceptibility testing quality control (CLSI 2005).

Virulence factor detection - After overnight cultivation on tryptic soy agar (Difco) plates at $35^{\circ} \mathrm{C}$, bacterial cells were suspended in $500 \mu \mathrm{L}$ sterile distilled water and pelleted for $15 \mathrm{~min}$ at $6,000 \mathrm{~g}$. DNA was isolated using phenol-chloroform extraction (Fox et al. 1994). The DNA concentration was estimated with an RNA/ DNA calculator (Pharmacia Biotech, Cambridge, England) and adjusted to $20 \mathrm{ng} / \mu \mathrm{L}$. All polymerase chain reaction (PCR) mixtures were prepared in a dedicated PCR chamber (Plaslabs, Lansing, MI, USA). The reaction mixtures were cycled in an MJ Research thermocycler (Watertown, MA, USA). Amplicons were assessed in a separate area to prevent contamination. All amplified PCR products were resolved on $8 \%$ polyacrylamide gels stained with ethidium bromide and visualised under ultraviolet light (Cole-Parmer, Vernon Hills, IL, USA). A 100 bp ladder (Life Technologies, Gaithersburg, MD, USA) was used as a molecular size marker. Positive and negative controls, as well as an internal negative control (sterile water) (LiChrosolv, Merck, Darmstadt, Germany), were included in each batch of reactions.

The ipaH, ial, setlA, sen, sat and iuc virulence markers were amplified as previously reported, with slight modifications (Lüscher \& Altwegg 1994, Vargas et al. 1999, Ruiz et al. 2002, Kingombe et al. 2005). Approximately $20 \mathrm{ng}$ of bacterial DNA was used as the template for amplification reactions. Details of the protocols are given in Table I. Taq DNA polymerase from Invitrogen (São Paulo, SP, Brazil) was used for sat and set1A amplification; polymerase from Phoneutria (Belo Horizonte, MG, Brazil) was used for ial, iuc, ipaH and sen amplification.

To ascertain the sensitivity and specificity of the amplification reactions, the following reference strains were used: S. flexneri (ATCC 12022), S. sonnei (ATCC 25931), S. dysenteriae (ATCC 13313), S. enterica Enteritidis (ATCC 13076), S. enterica Typhimurium (ATCC 14028), enteropathogenic E. coli (INCQS 00184), enteroinvasive $E$. coli (ATCC 43893), enterohaemorrhagic E. coli (ATCC 43895), E. coli (ATCC 25922) and Aeromonas hydrophila (IOC/FDA 110-36).

Ethics - This study was approved by the Ethical Committee of the Federal University of Minas Gerais (protocol ETIC 047/03). Written consent to participate was obtained from the parents or guardians of all children included in the study. 


\section{RESULTS}

Shigella species were isolated from stool specimens of 17/157 (10.8\%) patients: S. sonnei from 15/17 (88.2\%) and $S$. flexneri from two/17 (11.8\%). A total of 135 Shigella colonies were obtained (2-18 isolates/patient, average 7.9). Of the colonies, 104 were $S$. sonnei (2-18 isolates/patient, average 6.9) and 31 were $S$. flexneri (15-16 isolates/patient, average 15.5) strains. Each bacterial isolate was submitted to serotyping and antimicrobial susceptibility profile determination, as well as virulence factor identification.

The mean age of Shigella-positive patients (27.7 months, ranging from 3-48 months) was higher than that of Shigella-negative patients $(9.7$ months, ranging from 1-47 months; $\mathrm{p}<10^{-3}$ ). Most cases of shigellosis (approximately $90 \%$ ) were detected in children older than one year $\left[\mathrm{p}<10^{-6}\right.$, odds ratio $(\mathrm{OR})=22.3$, confidence interval $(\mathrm{CI})=4.71-205.8]$. More cases were observed in the warm and rainy months (October-March), although this difference was not statistically significant. Shigella positivity was not associated with gender.

Faecal leukocytes were found in 40 of the 152 (26.3\%) stool specimens analysed. The test was more frequently positive for shigellosis patients $\left(15 / 17,88.2 \%\right.$; $<<10^{-7}$, $\mathrm{OR}=33.0, \mathrm{CI}=6.8-305.9) ; 25$ of the 135 (18.5\%) Shigella-negative children gave positive results for this assay.

All Shigella isolates were sensitive to ceftriaxone, ciprofloxacin and nalidixic acid. Resistance rates to ampicillin and trimethoprim/sulfamethoxazole are given in Table II. Multiple drug susceptibility patterns among isolates obtained from the same patient were not observed. The test for ESBL production was negative for all Shigella isolates.

The ipaH, iuc and sen genes, as well as the ial locus, were detected in Shigella strains isolated from all Shigella-positive patients. The sat gene was observed in bacterial isolates from stool specimens obtained from five of 17 (29.4\%) children with shigellosis: two/two (100\%) and three/15 (20.0\%) patients from whom $S$. flexneri and $S$. sonne $i$ were recovered, respectively. The set $1 A$ gene was only detected in $S$. flexneri isolates.

All Shigella isolates exhibited the $\mathrm{ipaH}^{+} \mathrm{iuc}^{+}$genotype. Concerning the ial, sat and sen markers, diversity among isolates from the same child was observed in eight patients infected with $S$. sonnei (Table III). Different isolates were obtained from the two children infected with $S$. flexneri. A total of 16 isolates were obtained from one of these patients, all of which were $\operatorname{sat}^{+}$set $1 A^{+}, 13$ were $\mathrm{ial}^{+}$and three were $\mathrm{ial}^{-}$. Fifteen isolates were obtained from the other $S$. flexneri-positive child: nine were $i a l^{+}$, $14 \mathrm{sat}^{+}$and seven $\operatorname{set} 1 \mathrm{~A}^{+}$.

\section{TABLE II}

Resistance rates of Shigella strains to ampicillin and trimethoprim/sulfamethoxazole as evaluated by patient

\begin{tabular}{lccc}
\hline & $\begin{array}{c}\text { Shigella } \\
\text { sonnei } \\
(\mathrm{n}=15)\end{array}$ & $\begin{array}{c}\text { Shigella } \\
\text { flexneri } \\
(\mathrm{n}=2)\end{array}$ & $\begin{array}{c}\text { Total } \\
(\mathrm{n}=17)\end{array}$ \\
Antimicrobial drug & $\mathrm{n}(\%)$ & $\mathrm{n}(\%)$ & $\mathrm{n}(\%)$ \\
\hline Ampicillin & $2 / 13.3$ & $2 / 100$ & $4 / 23.5$ \\
Trimethoprim/sulfamethoxazole & $13 / 86.7$ & $1 / 50$ & $14 / 82.4$ \\
\hline
\end{tabular}

TABLE III

Distribution of Shigella sonnei strains in children infected by bacterium isolates harbouring different virulence markers

\begin{tabular}{|c|c|c|c|c|c|c|c|}
\hline \multirow[b]{3}{*}{ Patient } & \multicolumn{6}{|c|}{ Virulence marker } & \multirow{3}{*}{$\begin{array}{c}\text { Isolates } \\
\text { (n) }\end{array}$} \\
\hline & \multicolumn{2}{|c|}{ ial } & \multicolumn{2}{|c|}{ sat } & \multicolumn{2}{|c|}{ sen } & \\
\hline & + & - & + & - & + & - & \\
\hline 1 & 2 & 1 & 0 & 3 & 3 & 0 & 3 \\
\hline 2 & 13 & 0 & 0 & 13 & 12 & 1 & 13 \\
\hline 3 & 7 & 2 & 0 & 9 & 9 & 0 & 9 \\
\hline 4 & 7 & 0 & 0 & 7 & 6 & 1 & 7 \\
\hline 5 & 4 & 0 & 0 & 4 & 3 & 1 & 4 \\
\hline 6 & 2 & 1 & 0 & 3 & 3 & 0 & 3 \\
\hline 7 & 3 & 3 & 6 & 0 & 6 & 0 & 6 \\
\hline 8 & 5 & 1 & 0 & 6 & 6 & 0 & 6 \\
\hline
\end{tabular}

TABLE I

Polymerase chain reaction conditions employed for the detection of virulence markers of Shigella

\begin{tabular}{|c|c|c|c|c|c|}
\hline Gene & $\begin{array}{c}{[\text { primer }]} \\
(\mu \mathrm{M})\end{array}$ & $\begin{array}{c}{\left[\mathrm{MgCl}_{2}\right]} \\
(\mathrm{mM})\end{array}$ & $\begin{array}{c}{[\mathrm{Taq}]} \\
(\mathrm{U})\end{array}$ & $\begin{array}{c}\text { Annealing } \\
\text { temperature } \\
\left({ }^{\circ} \mathrm{C}\right)\end{array}$ & Reference \\
\hline ial & 0.6 & 2.5 & 0.5 & 60 & Kingombe et al. (2005) \\
\hline ipaH & 0.125 & 1.2 & 0.25 & 62 & Lüscher and Altwegg (1994) \\
\hline$i u c$ & 0.4 & 2.5 & 0.5 & 70 & Kingombe et al. (2005) \\
\hline sat & 0.25 & 1.5 & 1.0 & 64 & Ruiz et al. (2002) \\
\hline sen & 0.125 & 1.5 & 0.5 & 56 & Vargas et al. (1999) \\
\hline $\operatorname{set} 1 A$ & 0.25 & 1.5 & 0.5 & 58 & Vargas et al. (1999) \\
\hline
\end{tabular}




\section{DISCUSSION}

Recognition of the importance of Shigella as an enteric pathogen with a global impact has increased in recent years. Its importance is particularly visible in developing countries, where, as a consequence of vigorous use of oral rehydration therapy in recent decades, mortality from diarrhoeal dehydration has substantially decreased. However, because this intervention provides little benefit to patients with dysentery caused by invasive bacteria, the relative importance of shigellosis as a clinical problem has increased (Niyogi 2005, Bhattacharya et al. 2012, Shakoor et al. 2012).

Compared to a local data reported by Queiroz et al. (1987) at the end of the 1980s, we observed a decrease in the prevalence of Shigella. Although Brazil is a developing country, the vast majority of isolates we obtained were $S$. sonnei $(\cong 90 \%)$. This finding is similar to recent results from El Salvador, but in contrast to previously reported data for our region, states of Rondônia, Pará (PA) and Piaú (Queiroz et al. 1987, Diniz-Santos et al. 2005, Silva et al. 2008, Bastos \& Loureiro 2011, Nunes et al. 2012). In fact, S. sonnei is the most common Shigella species isolated in industrialised countries (Ina et al. 2003, Navia et al. 2005, Niyogi 2005). It is plausible that improvements to local hygiene and sanitation conditions in the intervening decades have reduced the prevalence of shigellosis and altered the local distribution pattern of Shigella species.

Shigellosis was more frequently observed in the summer (47.1\%) and autumn (29.4\%) than in the winter and spring, though no significant difference was found. Indeed, the incidence of shigellosis in our region peaked $(\cong 65 \%)$ in the warmer and more humid weather.

The faecal leukocyte test has long been considered a rapid and simple tool for screening patients with inflammatory diarrhoea associated with invasive, cytotoxic agents, especially Shigella spp. Despite the limited evidence supporting the efficacy of this test, it is still considered valuable by many clinicians. We found leukocytes in the faeces of nearly $90 \%$ of the patients with shigellosis. Additionally, as expected, faecal leukocytes were much more commonly detected in children with shigellosis than in Shigella-negative patients (Huicho et al. 1996).

Acute infectious diarrhoeal disease, whether inflammatory or non-inflammatory, is usually self-limited. However, antimicrobial therapy is recommended in specific conditions, such as shigellosis, to limit both the clinical course of the illness and the duration of faecal excretion of the causative organism (Lima et al. 1995, Cheasty et al. 2004, Diniz-Santos et al. 2005, Nguyen et al. 2005, Peirano et al. 2005, Christopher et al. 2010). There has been an alarming increase in bacterial resistance to antimicrobials, mainly in developing countries, where the use of these drugs is relatively unrestricted. Indeed, over the last half century, Shigella has demonstrated extraordinary prowess in acquiring plasmid-encoded resistance to the antimicrobial drugs previously considered first-line therapies (Niyogi 2005).

The vast majority of our Shigella isolates were resistant to trimethoprim/sulfamethoxazole $(82.4 \%)$. In con- trast, we found low ampicillin resistance rates $(23.5 \%)$, despite the fact that all $S$. flexneri isolates were resistant to this drug. Some studies report multidrug resistance in Shigella species, especially to trimethoprim/sulfamethoxazole and ampicillin, which are commonly used to treat shigellosis. Resistance rates to ampicillin and trimethoprim/sulfamethoxazole in the ranges of approximately $75-85 \%$ and $85-98 \%$, respectively, have been reported (Lima et al. 1995, Nguyen et al. 2005, Meng et al. 2011). Similar to our findings, high susceptibility rates to ceftriaxone (100\%), ciprofloxacin $(96.4-100 \%)$ and nalidixic acid (93-97.1\%) have already been reported by several authors (Oplustil et al. 2001, Torres et al. 2001, Cheasty et al. 2004, Nguyen et al. 2005).

Regarding recently published data for Brazil, $63.1 \%$ of Shigella strains isolated in PA displayed resistance to trimethoprim/sulfamethoxazole $(62.5 \%$ and $64.2 \%$ of $S$. sonnei and $S$. flexneri, respectively) and $43.4 \%$ to ampicillin (17.5\% and $56.8 \%$ of $S$. sonnei and S. flexneri, respectively). All isolates were sensitive to ciprofloxacin and nalidixic acid (Bastos \& Loureiro 2011). The S. flexneri and S. sonnei strains studied by Nunes et al. (2012) in an investigation conducted in Northeast Brazil were all susceptible to nalidixic acid, ceftriaxone and ciprofloxacin. Ampicillin resistance was reported in $66.7 \%$ of $S$. flexneri isolates. Even higher rates of resistance to trimethoprim/sulfamethoxazole $(71.4 \%$ for $S$. flexneri and $100 \%$ for S. sonnei) were observed.

Despite the fact that Shigella species are considered a leading cause of inflammatory diarrhoea, little is known about their genetic diversity worldwide. In Brazil, we are aware of no such study. Shigella may harbour several virulence factors, including those encoding toxins or associated with invasion of the colonic epithelium and dissemination from cell to cell (Fasano et al. 1995, Rudel 2012).

Historically, typing of Shigella has been performed using both phenotypic and genotypic methods. As with other bacteria, the methodology was initially based on conventional phenotypic tests (e.g., serotyping) or antimicrobial susceptibility testing, which are both inexpensive and technically simple, although their discriminatory powers are low. However, the development of molecular biology techniques has introduced genotyping methods with higher discriminatory power and better reproducibility (Navia et al. 2005). Methods such as pulsed-field gel electrophoresis and multilocus variable number tandem-repeat analysis have been successfully employed to evaluate genetic diversity among Shigella populations (Filliol-Toutain et al. 2011, Koh et al. 2012). In this study, PCR was used to investigate virulence markers in Shigella isolates.

All bacterial isolates were $i p a H^{+}$, as expected because this gene has been found in multiple copies on both the chromosome and the virulence plasmid of Shigella (Kingombe et al. 2005, Thong et al. 2005). Conversely, the ial locus is exclusively observed on the virulence plasmid and was only detected in some Shigella isolates. Indeed, less frequent detection of this marker has been reported by several authors (Lüscher \& Altwegg 1994, Kingombe et al. 2005, Thong et al. 2005). The absence of this locus may be explained by the in- 
trinsic genetic instability of this microorganism, which has hundreds of IS-elements capable of causing many types of DNA rearrangements (Yang et al. 2005). Additionally, the lack of ial could be due to the occurrence of mutations or lateral gene transfer (Navia et al. 2005). Furthermore, the possibility of multiple-strain infection cannot be ruled out.

In addition to their capacity for invasion, the expression of toxins is frequently observed in certain Shigella strains. These toxins include enterotoxins, such as Shet 1 and Shet 2 and Sat, a toxin first described in uropathogenic E. coli. We found set1A, which codes for Shet1, exclusively in $S$. flexneri strains, in agreement with previous results (Vargas et al. 1999, Guyer et al. 2000, Niyogi et al. 2004, Thong et al. 2005). The sen gene, which codes for Shet2, is located on the large virulence plasmid of Shigella spp that also carries sequences required for the invasion and spread of the bacterium, such as the ipa gene and the ial locus (Fasano et al. 1995, Noriega et al. 1995). The sen gene was detected in the vast majority of our Shigella isolates. Only three $(\cong 2 \%)$ of the 135 isolates studied were sen $^{-}$, which is possibly a consequence of the same events mentioned for the ial locus. In 2005, a sen gene was described on the chromosome of an S. sonnei strain (Yang et al. 2005). The sat gene was detected in almost all $S$. flexneri strains and in a low proportion of $S$. sonnei isolates, as previously reported (Ruiz et al. 2002, Niyogi et al. 2004). Strains that were $s a t^{+}$were isolated from five children and only one isolate obtained from one of the five children was sat. The occurrence of a mutation in the gene may explain this finding.

The iuc gene was detected in all Shigella isolates, in agreement with previously reported results (Kingombe et al. 2005). The iuc gene is chromosomally located and stable in Shigella spp. Its detection could therefore be included in strategies designed to identify this bacterium (Lawlor \& Payne 1984, Kingombe et al. 2005).

In conclusion, this study found a high prevalence of Shigella infection and a marked shift in the distribution of species, from $S$. flexneri to $S$. sonnei, among children less than four years of age in our region. Our data show a large proportion of trimethoprim/sulfamethoxazoleresistant Shigella isolates, a phenomenon that requires special attention because trimethoprim/sulfamethoxazole is considered the drug of choice to treat patients with inflammatory diarrhoea. We also described, for the first time, an evaluation of virulence markers of Shigella isolated from Brazilian patients, which may provide clues about the genetic diversity of this organism. Some of these markers were found in isolates from all Shigellapositive patients, but not in all bacterial isolates, which raises the hypothesis of infection of the same child by different clones of the bacterium or, alternatively, the hypothesis that this result is associated with the plasticity of the Shigella genome due to the large number of ISelements. Our study provides useful information about the prevalence, antimicrobial susceptibility patterns and virulence markers of Shigella, a threat to public health and an agent of infectious diarrhoea that continuously challenges health care professionals worldwide.

\section{ACKNOWLEDGEMENTS}

To Dr IRVF Capasso, Fundação Oswaldo Cruz, Rio de Janeiro, Brazil, for providing the reference strains.

\section{REFERENCES}

Bastos FC, Loureiro ECB 2011. Antimicrobial resistance of Shigella spp isolate in the state of Pará, Brazil. Rev Soc Bras Med Trop 44: 607-610.

Batthacharya SK, Sur D, Mahalanabis D 2012. Public health significance of shigellosis. Indian Pediatr 49: 269-270.

Boschi-Pinto C, Velebit L, Shibuya K 2008. Estimating child mortality due to diarrhoea in developing countries. Bull World Health Organ 86: 710-717.

Cheasty T, Day M, Threlfall EJ 2004. Increasing incidence of resistance to nalidixic acid in shigellas from humans in England and Wales. Clin Microbiol Infect 10: 1033-1035.

Christopher PR, David KV, John SM, Sankarapadian V 2010. Antibiotic therapy for Shigella dysentery. Cochrane Database Syst Rev 8: CD006784.

CLSI - Clinical Laboratory Standard Institute 2005. Performace standards for antimicrobial susceptibility testing, 15th Information Suplement M100-S15, CLSI, Wayne, 177 pp.

Diniz-Santos DR, Santana JS, Barretto JR, Andrade MGM, Silva LR 2005. Epidemiological and microbiological aspects of acute bacterial diarrhea in children from Salvador, Bahia, Brazil. Braz $J$ Infect Dis 9: 77-83.

Fasano A, Noriega FR, Maneval Jr DR, Chanasongcram S, Russell R, Guandalini S, Levine MM 1995. Shigella enterotoxin 1: an enterotoxin of Shigella flexneri 2a active in rabbit small intestine in vivo and in vitro. J Clin Invest 95: 2853-2861.

Filliol-Toutain I, Chiou CS, Mammina C, Gerner-Smidt P, Thong KL, Phung DC, Pichel M, Ranjbar R, Sow AG, Cooper K, Ribot E, Binsztein N, Liang SY 2011. Global distribution of Shigella sonnei clones. Emerg Infect Dis 17: 1910-1912.

Fox JG, Dewhirst FE, Fraser GJ, Paster BJ, Shames B, Murphy JC 1994. Intracellular Campylobacter-like organism from ferrets and hamsters with proliferative bowel disease is a Desulfovibrio sp. J Clin Microbiol 32: 1229-1237.

Guyer DM, Henderson IR, Nataro JP, Mobley HLT 2000. Identification of Sat, an autotransporter toxin produced by uropathogenic Escherichia coli. Mol Microbiol 38: 53-66.

Huicho L, Campos M, Rivera J, Guerrant R 1996. Fecal screening tests in the approach to acute infectious diarrhea: a scientific overview. Pediatr Infect Dis J 15: 486-494.

Ina K, Kusugami K, Ohta M 2003. Bacterial hemorrhagic enterocolitis. J. Gastroenterol 38: 111-120.

Kingombe CIB, Campos MLC, Farber JM 2005. Molecular strategies for the detection, identification and differentiation between enteroinvasive Escherichia coli and Shigella spp. J Food Prot 68: 239-245.

Koh XP, Chiou CS, Ajam N, Watanabe H, Ahmad N, Thong KL 2012. Characterization of Shigella sonnei in Malaysia, an increasingly prevalent etiologic agent of local shigellosis cases. BMC Infect Dis 12: 122.

Lawlor KM, Payne SM 1984. Aerobactin genes in Shigella spp. J Bacteriol 160: 266-272.

Lima AAM, Lima NL, Pinho MCN, Barros Jr EA, Teixeira MJ, Martins MCV, Guerrant RL 1995. High frequency of strains multiply resistant to ampicillin, trimethoprim-sulfamethoxazole, strepto- 
mycin, chloramphenicol and tetracycline isolated from patients with shigellosis in northeastern Brazil during the period 1988 to 1993. Antimicrob Agents Chemother 39: 256-259.

Li-Yan Y, Feng-Hua L, Zhong-Yong Z, Xin-Min C, Xiao-Li Y 1993. Detection of Shigella and enteroinvasive Escherichia coli using polymerase chain reaction. J Diarrhoeal Dis Res 11: 38-40.

Lüscher D, Altwegg M 1994. Detection of Shigella, enteroinvasive and enterotoxigenic Escherichia coli using the polymerase chain reaction (PCR) in patients returning from tropical countries. Mol Cell Probes 8: 285-290.

Meng CY, Smith BL, Bodhidatta L, Richard SA, Vansith K, Thy B, Srijan A, Serichantalergs O, Mason CJ 2011. Etiology of diarrhoea in young children and patterns of antibiotic resistance in Cambodia. Pediatr Infect Dis J 30: 331-335.

Nataro JP, Seriwatana J, Fasano A, Maneval DR, Guers LD, Noriega F, Dubovsky F, Levine MM, Morris Jr JG 1995. Identification and cloning of a novel plasmid-encoded enterotoxin of enteroinvasive Escherichia coli and Shigella strains. Infect Immun 63: 4721-4728.

Navaneethan U, Gianella RA 2008. Mechanisms of infectious diarrhea. Nat Clin Pract Gastroenterol Hepatol 5: 637-647.

Navia MM, Gascón J, Vila J 2005. Genetic diversity of Shigella species from different intercontinental sources. Infect Genet Evol 5: 349-353.

Nguyen TV, Le PV, Le CH, Weintraub A 2005. Antibiotic resistance in diarrheagenic Escherichia coli and Shigella strains isolated from children in Hanoi, Vietnam. Antimicrob Agents Chemother 49: 816-819.

Niyogi SK 2005. Shigellosis. J Microbiol 43: 133-143.

Niyogi SK, Vargas M, Vila J 2004. Prevalence of the sat, set and sen genes among diverse serotypes of Shigella flexneri strains isolated from patients with acute diarrhea. Clin Microbiol Infect 10: $574-576$.

Noriega FR, Liao FM, Formal SB, Fasano A, Levine MM 1995. Prevalence of Shigella enterotoxin 1 among Shigella clinical isolates of diverse serotypes. J Infect Dis 172: 1408-1410.

Nunes MRCM, Magalhães PP, Penna FJ, Nunes JMM, Mendes EM 2012. Diarrhea associated with Shigella in children and susceptibility to antimicrobials. $J$ Pediatr 88: 125-128.

Nyachuba DG 2010. Foodborne illness: is it on the rise? Nutr Rev 68: 257-269.

Oplustil CP, Nunes R, Mendes C, RESISTNET Group 2001. Multicenter evaluation of resistance patterns of Klebsiella pneumoniae, Escherichia coli, Salmonella spp and Shigella spp isolated from clinical specimens in Brazil: RESISTNET surveillance program. Braz J Infect Dis 5: 8-12.

Parsot C 2005. Shigella spp and enteroinvasive Escherichia coli pathogenicity factors. FEMS Microbiol Lett 252: 11-18.

Peirano G, Agerso Y, Aarestrup FM, Rodrigues DP 2005. Occurrence of integrons and resistance genes among sulphonamide-resistant Shigella spp from Brazil. J Antimicrob Chemother 55: 301-305.

Queiroz DMM, Mendes EN, Penna FJ, Peret-Filho LA, FigueiredoFilho PP, Duarte MA, Peres JN 1987. Research on enteropatho- genic bacteria from children with acute diarrhea, in Belo Horizonte, MG. Arq Gastroenterol 24: 46-50.

Rudel T 2012. To die or not to die: Shigella has an answer. Cell Host Microbe 11: 219-221.

Ruiz J, Navia MM, Gascón J, Vila J 2002. Prevalence of the sat gene among clinical isolates of Shigella spp causing travellers diarrhea: geographical and specific differences. J Clin Microbiol 40: $1565-1566$.

Sánchez J, Holmgren J 2005. Virulence factors, pathogenesis and vaccine protection in cholera and ETEC diarrhea. Curr Opin Iтmиnol 17: 388-398.

Shakoor S, Zaidi AK, Hasan R 2012. Tropical bacterial gastrointestinal infections. Infect Dis Clin North Am 26: 437-453.

Silva T, Nogueira PA, Magalhães GF, Grava AF, Silva LHP, Orlandi PP 2008. Characterization of Shigella spp by antimicrobial resistance and PCR detection of ipa genes in an infantile population from Porto Velho (western Amazon Region), Brazil. Mem Inst Oswaldo Cruz 103: 731-733.

Thong KL, Hoe SLL, Puthucheary SD, Yasin RMD 2005. Detection of virulence genes in Malaysian Shigella species by multiplex PCR assay. BMC Infect Dis 5: 8.

Toledo MRF, Fontes CF, Trabulsi LR 1982a. EPM - modificação do meio de Rugai e Araújo para a realização simultânea dos testes de produção de gás a partir de glicose, $\mathrm{H}_{2} \mathrm{~S}$, urease e triptofano desaminase. Rev microbiol 13: 309-315.

Toledo MRF, Fontes CF, Trabulsi LR 1982b. MILi - um meio para a realização dos testes de motilidade, indol e lisina descarboxilase. Rev microbiol 13: 230-235.

Torres ME, Pírez MC, Schelotto F, Varela G, Parodi V, Allende F, Falconi E, Dell'acqua L, Gaione P, Méndez MV, Ferrari AM, Montano A, Zanetta E, Acuna AM, Chiparelli H, Ingold E 2001. Etiology of children's diarrhea in Montevideo, Uruguay: associated pathogens and unusual isolates. J Clin Microbiol 39: 2134-2139.

Vargas M, Gascon J, Anta MTJ, Vila J 1999. Prevalence of Shigella enterotoxins 1 and 2 among Shigella strains isolated from patients with traveler's diarrhea. J Clin Microbiol 37: 3608-3611.

Vokes SA, Reeves SA, Torres AG, Payne SM 1999. The aerobactin iron transport system genes in Shigella flexneri are present within a pathogenicity island. Mol Microbiol 33: 63-73.

Wei J, Goldberg MB, Burland V, Venkatesan MM, Deng W, Fournier G, Mayhew GF, Plunkett III G, Rose DJ, Darling A, Mau B, Perna NT, Payne SM, Runyen-Janecky LJ, Zhou S, Schwartz DC, Blattner FR 2003. Complete genome sequence and comparative genomics of Shigella flexneri 2a strain 2457T. Infect Immun 71: 2775-2786.

WHO - World Health Organization 2005. The treatment of diarrhea. A manual for physicians and other senior health workers, 4th ed., WHO, Geneva, $50 \mathrm{pp}$.

Yang F, Yang J, Zhang X, Chen L, Jiang Y, Yan Y, Tang X, Wang J, Xiong Z, Dong J, Xue Y, Zhu Y, Xu X, Sun L, Chen S, Nie H, Peng J, Xu J, Wang Y, Yuan Z, Wen Y, Yao Z, Shen Y, Qiang B, Hou Y, Yu J, Jin Q 2005. Genome dynamics and diversity of Shigella species, the etiologic agents of bacillary dysentery. Nucleic Acids Res 33: 6445-6458. 